\title{
CENTRO DE DOCUMENTAÇÃO DA ESCOLA DE ENFERMAGEM ANNA NERY(EEAN) - UMA CONTRIBUIÇÃO À HISTÓRIA DA ENFERMAGEM****
}

\author{
Jussara Sauthier* \\ Maria Tereza Coimbra de Carvalho** \\ Neiva Maria Piccinini Santos***
}

SAUTHIER, J.; CARVALHO, M.T.C.de; SANTOS, N.M.P. Centro de documentação da Escola de Enfermagem Anna Nery (EEAN) - uma contribuição à história da enfermagem. Rev.latino-am.enfermagem, Ribeirão Preto, v. 8, n. 5, p. 81-84, outubro 2000.

Trata-se de um estudo descritivo que objetiva difundir uma filosofia de preservação da memória da enfermagem, apresentar os critérios observados na organização e preservação do acervo documental e por último, mas não menos importante, divulgar a experiência de organização de um Centro de Documentação. Além de apresentar as técnicas a serem observadas no tratamento da massa documental, registramos os cuidados referentes à questão ambiental e à conduta do usuário no referido Centro, destacando a importância deste Centro como fonte de informação e pesquisa a várias áreas do conhecimento.

UNITERMOS: centro de documentação, acervo documental, preservação do acervo

Há alguns anos, a Escola de Enfermagem Anna Nery vem se empenhando em organizar o seu acervo documental. Este esforço se traduziu inicialmente pelo trabalho de algumas professoras, entre elas, Anna J. Nava e Madalena Werneck, que organizaram o arquivo iconográfico. Mais tarde, Cecília Pecego Coelho e Vilma de Carvalho deram início à organização do arquivo de documentos escritos. O acervo de História Oral se originou da doação de fitas gravadas e transcritas pelas professoras Ieda de A. Barreira, Suely de S. Baptista, Isabel C. dos Santos Oliveira e Cristina L.de Miranda. Atualmente, este trabalho está sendo desenvolvido por uma Comissão Técnica, presidida pela professora Jussara Sauthier.

Este acervo documental merece, acima de tudo, ser preservado pelo seu testemunho histórico da implantação e consolidação da Enfermagem Moderna no Brasil. Este conjunto documental tem servido como fonte de informação para estudiosos de várias áreas do conhecimento, constituindo-se em uma importante fonte de pesquisa para enfermeiras, arquitetos, jornalistas, historiadores, médicos sanitaristas entre outros.

A elaboração deste texto objetiva orientar os profissionais e alunos que atuam em Centro de Documentação e demais usuários do sistema, com instruções básicas sobre medidas de conservação, preservação e consulta aos documentos históricos.

Essa idéia surgiu a partir da indicação de uma Comissão Técnica para o Centro de Documentação na gestão da Professora Ivone Evangelista Cabral. As pessoas, até então, envolvidas com a conservação e preservação de documentos históricos, vinham sentindo a necessidade do estabelecimento de diretrizes que norteassem o seu trabalho.

Adotamos o conceito de preservação no seu sentido mais amplo, envolvendo os aspectos administrativos, decisões políticas, recursos humanos e financeiros, guarda da documentação, treinamento de pessoal e atividades de conservação e restauração com encaminhamento para especialistas na área específica, quando necessário.

Os alunos do Curso de Graduação em Enfermagem participam da reorganização do Centro de Documentação, através da disciplina Fontes para História da Enfermagem Brasileira. Neste momento, é demonstrado que o estabelecimento de uma política de

\footnotetext{
* Presidente da Comissão do Centro de Documentação, Professor Doutor Adjunto do Departamento de Enfermagem Fundamental da Escola de Enfermagem Anna Nery da Universidade Federal do Rio de Janeiro

** Representante do corpo discente da Pós-graduação junto ao Centro de Documentação e Professor Adjunto do Departamento de Metodologia da Enfermagem. Escola de Enfermagem Anna Nery da Universidade Federal do Rio de Janeiro

*** Representante das (os) Professoras (es) junto ao Centro de Documentação e Chefe do Departamento de Metodologia da Enfermagem. Escola de Enfermagem Anna Nery da Universidade Federal do Rio de Janeiro

**** Apoio Técnico de Zelaine Costa do Vale e Leila Márcia Pinto Coelho
} 
preservação pode ser instrumento para definir princípios, listar atividades de preservação e conservação e designar responsabilidades.

O primeiro passo a ser considerado no estabelecimento de uma política de preservação é a avaliação do prédio onde o acervo está localizado. Neste particular, o Centro de Documentação da EEAN foi colocado numa sala do andar térreo do Pavilhão de Aulas, com aproximadamente 108 metros quadrados, prédio este tombado pelo Instituto de Patrimônio Histórico e Artístico Nacional (IPHAN). Esta sala abriga todas as Séries Documentais, as mesas de consulta e de trabalho, além de comunicar-se diretamente com a biblioteca por dois vãos, o que torna o Centro de Documentação vulnerável. Esta limitação traz prejuízos, tanto para a equipe de trabalho empenhada na conservação e restauração de documentos, quanto para os usuários do sistema de arquivo.

A área física composta de quatro espaços, ou seja, para recepção, guarda das séries documentais, higienização ou restauração e biblioteca de apoio, é a mais indicada.

A localização do Centro de Documentação no térreo, dispensa o estudo de carga para avaliação da real resistência de todos os elementos estruturais. No entanto, alguns aspectos devem ser considerados, tais como: instalações elétricas para suportar a grande demanda de recursos da informática, reestudo da utilização do espaço físico, sistema de prevenção contra incêndio, controle da umidade e ventilação. E por último, porém não menos importante, a segurança contra roubos de equipamentos e documentos históricos.

\section{A REORGANizAÇÃO dO CENTRO DE DOCUMENTAÇÃO DA EEAN}

Atualmente, o Centro de Documentação encontra-se em fase de reorganização, observando-se o princípio da procedência. Dividido em Séries Documentais, facilita o usuário do sistema na busca da informação e à criação ou ampliação das séries já existentes. As principais séries, organizadas ou em fase de tratamento arquivístico, são:

- A Missão 1922-1931; reúne um conjunto de documentos escritos produzidos pelas enfermeiras estrangeiras que implantaram a Enfermagem Moderna no Brasil;

- As Pioneiras - De Rachel H. Lobo a Lais Netto dos Reys 1932-1950; contém documentos produzidos nas gestões de Rachel H. Lobo, Berta Pullen e Lais Netto dos Reis;

- Curso de Graduação 1923 a 1990; composto de dossiê das alunas que concluíram o curso de enfermagem a partir da primeira turma que colou grau em 1925;
- Socorristas Voluntárias de Guerra (1942-1945); esta série documental reúne documentos que demonstram a participação da EEAN no preparo de moças brasileiras motivadas a inscreverem-se como voluntárias na II Guerra Mundial;

- Associação de Voluntárias de Anna Nery; (AVAN) esta série é resultado de um movimento feminino em prol do bem estar dos clientes dos hospitais públicos ou filantrópicos do Rio de Janeiro;

- Os Excluídos (1923-1970), contém o dossiê das alunas que foram reprovadas ou convidadas a deixar o curso de Graduação da EEAN;

- O acervo de História Oral reúne um conjunto de depoimentos gravados e transcritos pelas autoras das pesquisas, acompanhados da autorização do depoente.

- O Arquivo Iconográfico contém cerca de 2.000 fotografias, de 1923 aos nossos dias. Elas testemunham os fatos oficiais e sociais da Escola;

- Série Pós-Graduação, reúne os documentos escritos, produzidos desde a criação do curso de Mestrado, em 1972.

- Diretoras e outras Personalidades, contém documentos pertencentes ao arquivo privado dessas pessoas;

- Obras Raras e Preciosas para a enfermagem, reúne exemplares que datam do período inicial da ascensão da enfermagem no Brasil, cadernos ou textos manuscritos, livros que indicam a adoção de novas abordagens na enfermagem, exemplares com anotações manuscritas ou autógrafos de enfermeiras que se projetaram num dado campo profissional, primeiros periódicos brasileiros e a coleção especial de Teses e Dissertações defendidas na EEAN.

Para facilitar a localização do documento, elaborou-se catálogos descritivos. Neles, os documentos, que integram cada série documental, são apresentados de acordo com o seu tipo, acompanhados de um breve resumo de seu conteúdo, autoria, data, o local onde foi produzido e número de páginas. A localização do documento é ainda facilitada pela indicação do módulo, caixa e número do documento na série documental a qual pertence.

Atualmente, estamos executando um projeto de informatização com recursos Multi Mídia. Pretendemos, brevemente, colocar a disposição do público CD ROMs contendo as séries documentais descritas.

\section{MEDIDAS DE PREVENÇÃO DE DANOS AO ACERVO}

Como o Centro de Documentação da EEAN não conta com profissionais especializados no campo da arquivologia, procurou-se verificar os aspectos apontados 
pelos especialistas como os mais relevantes no que se refere à preservação de documentos.

Constatou-se, então, que agentes externos e ambientais contribuem para a deterioração de documentos. Conhecimentos básicos sobre as condições de armazenamento, exposição, segurança e consulta aos documentos são imprescindíveis para a manutenção de um acervo (SILVA et al., 1994).

Os fatores, que colocam em risco a grande maioria dos acervos, são: temperatura, umidade relativa, iluminação, poluição, agentes biodeterioradores e a ação dos próprios usuários ou pessoas que neles prestam serviço.

A temperatura e a umidade, se não controladas, tornam-se fatores de risco. A temperatura ambiental deve ser mantida em torno de $19^{\circ}$ a $23^{\circ}$ centígrados e a umidade relativa do ar entre $50 \%$ a $60 \%$, através de aparelhos específicos, tais como, ar condicionado, ventiladores, higrômetros e desumidificadores. Autores como SILVA et al. (1994), sugerem o uso de Sílica Gel, em forma de pedra, para documentos guardados em arquivos pela sua ação desumedificante.

Quanto à iluminação, a luz solar e a luz branca são prejudiciais à conservação do acervo. Por essa razão, não devem incidir diretamente sobre os documentos. É recomendável o uso de filtros protetores nas lâmpadas e persianas para as janelas.

No que se refere à poluição atmosférica, entre os poluentes mais danosos aos documentos estão a poeira e os gases ácidos. O uso de filtros em sistemas de ventilação, periodicamente limpos ou trocados, podem diminuir substancialmente os agentes poluentes do ambiente.

A higienização periódica do acervo é um ponto fundamental para a sua preservação e para a segurança do usuário. A higienização dos livros e documentos deve ser realizada com um aspirador de pó ou trincha de cerdas macias, pelo menos uma vez ao ano. A limpeza sistemática do ambiente, com pano úmido e aspirador, deve ser diária.

Os meios de comunicação diariamente denunciam que agentes biodeterioradores têm dizimado importantes acervos públicos ou privados. O diagnóstico das condições do acervo e a adoção de medidas preventivas de dano desses agentes são essenciais para a sua preservação. Além dos métodos de controle, utilizados por empresas especializadas no extermínio de baratas, traça de livro, piolho de livro, brocas e cupins, recomenda-se a utilização de estantes de metal. A estante de madeira tratada deverá ser usada para a parte do acervo que reúne filmes e fitas magnéticas.

Quando uma obra rara estiver com a encadernação original danificada ou com folhas soltas, recomenda-se utilizar, após a higienização, uma embalagem de proteção com papel de $\mathrm{pH}$ neutro, até a sua restauração. Estas embalagens devem ser abertas e inspecionadas periodicamente para verificar a ocorrência de danos ao documento. Essas medidas de prevenção terão pouco valor se não forem acompanhadas do controle ambiental.

A ação danosa das pessoas sobre o acervo são comuns, mesmo quando há um empenho na prevenção dessa agressão. Essa conduta pode ser decorrente de ignorância ou de ação intencional. Os cuidados no manuseio de um documento são determinantes de sua vida útil e, portanto, de sua utilização por pesquisadores ou outras pessoas interessadas no testemunho dos fatos. A primeira medida a ser tomada é o treinamento do pessoal do Centro de Documentação.

A difusão de uma filosofia de preservação da memória da Enfermagem Brasileira, por certo, contribuirá para uma conduta mais coerente com os objetivos de um arquivo histórico.

Para a segurança do pesquisador, recomenda-se o uso de máscaras, luvas de algodão e avental protetor. Essas medidas, além de proteger o usuário do sistema de arquivo, evita a ação danosa do suor e oleosidade natural da pele sobre documentos e fotografias. Se o acervo está seriamente contaminado com fungos, deve-se também usar óculos de proteção.

O inconveniente costume de molhar a ponta dos dedos para folhear um livro é totalmente condenado. $\mathrm{O}$ melhor seria virar a página pela parte superior da folha. Outro cuidado é o de não apoiar os cotovelos sobre o documento ou livro que está sendo consultado. Vale ainda lembrar que papéis avulsos, deixados dentro de livros, produzem marcas.

$\mathrm{O}$ ato de fumar, além de trazer prejuízos para saúde, põe em risco o acervo. Fazer refeições dentro do Centro de Documentação atrai insetos, por essa razão, deve-se proibir tais práticas. As plantas também não são recomendadas no ambiente de um arquivo.

Os livros e documentos necessitam "respirar", por essa razão, a guarda em sacos plásticos produz sérios danos ao material. Papel especial, com pH neutro, é o mais recomendável para embalar documentos escritos. Para proteger fotografias, usa-se papel manteiga. Fitas adesivas, grampos, clipes metálicos, carimbos, anotações com canetas ou dobras, ocasionam danos ao documento, como o rompimento das fibras do papel, manchas e ferrugem. Para anotações no verso de fotografias, recomenda-se lápis preto macio.

Arrancar páginas de livros ou apropriar-se de documentos ou peças do acervo é um deserviço à toda Biblioteca, ao Centro de Documentação, ou à qualquer instituição. O documento histórico, seja ele escrito, iconográfico ou pertencente ao arquivo de história oral, é um patrimônio da instituição. 
O Programa Institucional de proteção contra incêndios e inundações tem minimizado as conseqüências dos desastres em arquivos históricos. Por essa razão, recomenda-se a elaboração ou revisão do já existente.

O cuidado com a documentação produzida por uma dada instituição é uma responsabilidade que deve ser compartilhada por administradores, docentes, enfermeiras e todos aqueles que atuem em instituições de ensino, assistência ou mesmo em entidades de classe. Acreditamos que a divulgação de nossa experiência possa contribuir para a difusão de uma filosofia de preservação da memória da enfermagem.

\section{ANNA NERY SCHOOL OF NURSING'S DOCUMENTARY CENTER - A CONTRIBUTION TO NURSING HISTORY}

The purposes of this descriptive study are to transmit a philosophy of preserving the Nursing memory, to present the criteria observed in the organization and preservation of documentary collection and last but not least to share the experience of organizing a Documentary Center. Besides presenting the techniques to be used while dealing with documentary collection, attention is also drawn to environmental issues as well as the user's behavior in the aforementioned Center, whose importance as a source of information and research to several areas of human knowledge is emphasized.

KEY WORDS: documentary center, documentary collection, collection's preservation

\section{CENTRO DE DOCUMENTACIÓN DE LA EEAN - UNA CONTRIBUCIÓN PARA LA HISTORIA DE LA ENFERMERÍA}

Trátase de un estudio descriptivo que tiene por objeto difundir una filosofía de preservación de la memoria de la Enfermería, para presentar los criterios observados en la organización y preservación del acervo documental y por último, todavía no menos importante, divulgar la experiencia de la organización de un Centro de Documentación. Antes de presentar las técnicas a ser observadas en el tratamiento de la masa documental, registramos los cuidados referentes a la cuestión ambiental y a la conducta del usuario en el referido Centro, lo cual se destaca como importante fuente de información e investigación a varias áreas del conocimiento.

TÉRMINOS CLAVES: centro de documentación, acervo documental, preservación del acervo

\section{REFERÊNCIA BIBLIOGRÁFICA}

01. SILVA, J.T. et al. Manual de conservação de acervos bibliográficos. Rio de Janeiro: UFRJ/ SIBI/ CTOR, 1994.

\section{BIBLIOGRAFIA CONSULTADA}

\section{BECK, I. Manual de conservação de documentos.} Rio de Janeiro: Arquivo Nacional, 1985.
02. GOUGET, A.G.G. et al. Documentos do período colonial: considerações para tratamento técnico. Rio de Janeiro: Arquivo Nacional, 1985.

03. SPINELLI, J. Introdução à conservação de acervos bibliográficos. Rio de Janeiro: Biblioteca Nacional, s/d.

04. VALÉRIO, A.C.G. et al. Identificação de documentos em arquivos públicos. Rio de Janeiro: Arquivo Nacional, 1985. 